Research Article

\title{
Structural Evolution of Burmese Amber during Petrifaction Based on a Comparison of the Spectral Characteristics of Amber, Copal, and Rosin
}

\author{
Feng Bai $(\mathbb{D}$, Huifang Liang, and Hongting Qu \\ School of Gemmology, China University of Geosciences (Beijing), No. 29 Xueyuan Road, Beijing 100083, China \\ Correspondence should be addressed to Feng Bai; baifengbj@163.com
}

Received 4 January 2019; Accepted 8 May 2019; Published 7 July 2019

Academic Editor: Vincenza Crupi

Copyright ( $\odot 2019$ Feng Bai et al. This is an open access article distributed under the Creative Commons Attribution License, which permits unrestricted use, distribution, and reproduction in any medium, provided the original work is properly cited.

\begin{abstract}
This paper presents a spectroscopic analysis and solubility study of rosin, copal, and Burmese amber samples to reveal the structural changes that occur during amber formation. The infrared spectra indicate that during the long geological process of amber formation, small resin molecules first crosslinked and slowly oxidized, eventually forming a stable organic polymer mixture. An analysis of Raman peak areas demonstrated that among the tested samples, the degree of polymerization is highest in Burmese amber and lowest in rosin. Ultraviolet-visible spectra indicate the presence of unsaturated bonds (e.g., carbonyl groups) or conjugated systems in Burmese amber, copal, and rosin. The evaluation of amber, rosin, and copal solubility in six solvents (ethanol, acetone, 1,4-dioxane, ethylacetate, N,N-dimethylamide, and dichloromethane) demonstrated that solubility decreases in the following order: rosin $>$ copal $>$ Burmese amber. Together, the results suggest that the structure of Burmese amber includes large organic molecules containing six-membered rings along with $\mathrm{CH}_{2}, \mathrm{CH}_{3}$, $\mathrm{C}=\mathrm{O}, \mathrm{C}=\mathrm{C}, \mathrm{C}-\mathrm{O}$, and $\mathrm{C}-\mathrm{C}$ groups.
\end{abstract}

\section{Introduction}

Amber is a natural resin fossil formed by the physical and chemical changes caused by temperature, pressure, and time after natural resin is buried in the ground. Amber, copal, and rosin are products of natural resin under different geological conditions and stages. The main component of resin is anthracene compounds, i.e., the terpene with formula $\left(\mathrm{C}_{5} \mathrm{H}_{8}\right)_{\mathrm{n}}$ and its derivatives. Terpenoids are classified into monoterpenes, sesquiterpenes, diterpenes, and triterpenes according to the number of basic constituent units. To resist pests, germs, viruses, etc., the intrinsic compounds secrete aromatic astringents. The olefins, sesquiterpenes, and diterpenes are self-protected from the environment. The diterpenoid and triterpenoid molecules are relatively large and nonvolatile; thus, most are present in solid form. Diterpenoids are the main constituents of resin. Yan et al. [1] and Chen et al. [2] found that the resin acid is typically divided into two types, tannic acid and pimaric acid, based on the outer functional groups. Lambert and Frye [3] reported that copal is mainly composed of various resin acids, terpene volatile components, and resinous substances. The main components of amber are succinic acid, succinyl alcohol, and amber oil. Natural resin undergoes polymerization, and thus crosslinks are formed and the unsaturated bond is broken to form the intermediate product copal. After the oxidation of copal, the unstable components volatilize and eventually form amber [4]. The contents of specific components vary depending on the place of origin and the type of production $[5,6]$. The structures and compositions of amber and copal differ because of the different plant species, geographical conditions, climatic conditions, and geological conditions during their formation, and these conditions lead to the difference in the degree of petrochemical (maturity) of natural resin. The complex geological environment causes amber produced in different areas to have different properties.

The conversion of natural resin to amber takes tens of millions of years of geological processes. Burmese amber 
was formed 60 million years to 135 million years ago in the earliest Cenomanian Stage [7]. Burmese amber, which is the oldest resin fossil, was mainly produced in the Hukawng Valley of Myitkyina Province in northern Myanmar. The amber deposit is located in a lignite deposit found 10 to 15 meters underground. Yang et al. [8] deduced the basic structure of amber based on an analysis of organic elements and spectral analysis of the crude amber extract. The authors concluded that the amber has an aliphatic structure, and the amber color and appearance are different due to the different internal oxygen structure. Lambert et al. [9] classified ambers worldwide into different categories according to their structures based on nuclear magnetic resonance analysis; this classification provided a theoretical basis for the study of amber structure and origin around the world. Guiliano et al. [10] distinguished amber, copal, and rosin based on sample absorption in the midinfrared range $\left(3048 \mathrm{~cm}^{-1}\right.$, $1642 \mathrm{~cm}^{-1}$, and $887 \mathrm{~cm}^{-1}$ ), which reflects the petrifaction of the resin. By comparing the $\mathrm{C}, \mathrm{H}$, and $\mathrm{O}$ mass fractions in amber from different origins, Wang et al. [11] found that among the tested ambers, Burmese amber had the highest mass fraction of carbon and highest degree of petrifaction. Based on Raman spectroscopy, Rao et al. [12] confirmed the presence of terpenes in copal. Yang and Wang [13] made a comparative analysis of the physicochemical properties and spectral characteristics of copal and amber. The results confirmed that the mass fraction of the monomer component of diterpene can be used to characterize the maturity of petrifaction, which is used to distinguish copal (low degree of maturity) and amber (high degree of maturity). Meanwhile, Wang et al. [14] distinguished amber and copal based on the absorption of unsaturated double bonds $(\mathrm{C}=\mathrm{C})$ in the midinfrared region. Dong and $\mathrm{Yu}$ [15] analyzed amber produced in different areas using infrared spectroscopy. They found that the absorption between $1705 \mathrm{~cm}^{-1}$ and $1728 \mathrm{~cm}^{-1}$, which is attributed to the stretching vibration of the $\mathrm{C}=\mathrm{O}$ functional group, provides an important reference for the identification of amber origin. In a study of pressed amber, Wang et al. [16] determined that the ratio of absorption intensity at $2932 \mathrm{~cm}^{-1}$ to that at $1723 \mathrm{~cm}^{-1}$ in the infrared spectrum can distinguish whether blue amber has been heated or not. Based on differential thermal analysis, Peng and Zhu [17] determined that the temperature of maximum weight loss increases as the amber becomes older. Xu [18] identified the organic molecular groups of amber and its imitations based on their infrared absorption spectra. The findings indicated that the esterification and polymerization of the macromolecular structure of amber contribute to amber genesis. In summary, the physical properties of amber are closely related to its composition and structure.

Burmese amber is the most important source of Asian amber. It is the oldest resin fossil, but there is relatively little research on the structure of amber found in Myanmar. This article focuses on the study of the structural changes in the formation of amber by means of several spectroscopy techniques and solubility tests. In particular, a multitechnical approach has rigorously been adopted and the results are systematically correlated and compared. In this paper, infrared spectroscopy, Raman spectroscopy, UVVis spectroscopy, and solubility studies of rosin, copal, and Burmese amber are employed to evaluate the structural changes and chemical reactions that occur during the formation of amber.

\section{Materials and Methods}

Experimental samples (Figure 1) were selected from rough Burmese amber (A-1 to A-3), natural copal (KB), and natural rosin (SX). The amber samples were light-yellow transparent (A-1), orange-red translucent (A-2), and brown translucent/ opaque (A-3). The copal sample (KB) was opaque and dark brown. The rosin sample (SX) was yellow, transparent, and brittle with white debris visible on the surface.

The infrared spectrum of each sample was collected with a Fourier-transform infrared spectrometer (TERMOR27, Bruker) at the Beijing CUG Gem Testing Center using compressed $\mathrm{KBr}$ powder tablets. The experimental conditions were as follows: scanning temperature $=18^{\circ} \mathrm{C}-25^{\circ} \mathrm{C}$; humidity $<70 \%$; voltage $=85-265 \mathrm{~V}$; resolution $=4 \mathrm{~cm}^{-1}$; aperture $=6 \mathrm{~mm}$; and scanning range $=400-5000 \mathrm{~cm}^{-1}$. For each sample, the cumulative signal was collected from 32 scans.

Raman spectroscopy was performed at the Experimental Teaching Center of Jewellery and Mineral Materials, China University of Geosciences, Beijing, using a LabRAM HR Evolution Raman spectrometer (HORIBA). The wavelength of the excitation light source was $785 \mathrm{~nm}$, the power of the laser excitation beam is $100 \mathrm{~mW}$, and the measurement range was $1000-3500 \mathrm{~cm}^{-1}$. The resolution and scanning time were $1 \mathrm{~cm}^{-1}$ and $20 \mathrm{~s}$, respectively.

UV-Vis spectroscopy was performed at the Experimental Teaching Center of Jewellery and Mineral Materials, China University of Geosciences, Beijing, using the reflection and transmission method. Measurements were carried out using a UV-Vis/near-infrared spectrophotometer (UV-3600, Shimadzu Corporation).

Solubility was evaluated in a laboratory at the Dalian Institute of Chemical Physics, Chinese Academy of Sciences. The rosin, copal, and Burmese amber powders were dissolved separately in six organic solvents: ethanol, acetone, 1,4-dioxane, ethylacetate, N,N-dimethylamide (DMF), and dichloromethane. Sample solubility was evaluated with stirring for $12 \mathrm{~h}$.

\section{Results and Discussion}

3.1. Infrared Spectroscopy. The infrared spectra of the amber, copal, and rosin samples are shown in Figures 2(a)-2(c), respectively.

The infrared peak positions for all samples are shown in Table 1. By comparing the commonalities and differences of samples absorption, the infrared spectra of all samples are characterized by two strong absorption bands in the ranges of $3500-2800 \mathrm{~cm}^{-1}$ and $2000-600 \mathrm{~cm}^{-1}$. The first strong absorption band $3500-2800 \mathrm{~cm}^{-1}$ is susceptible to interference 


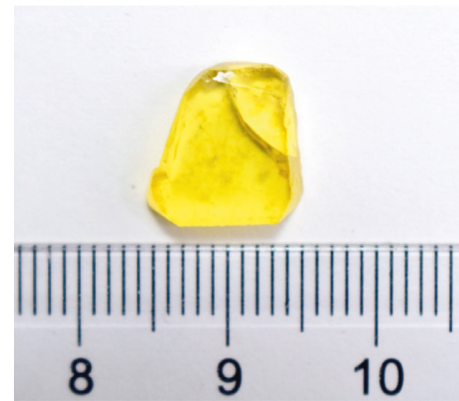

(a)

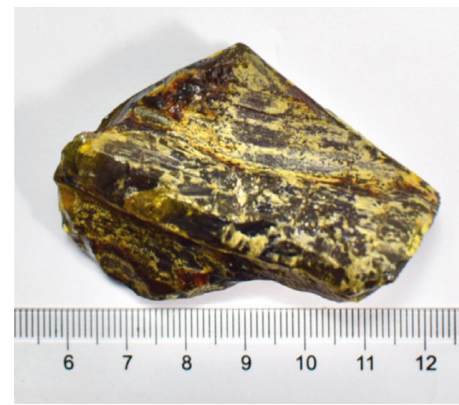

(d)

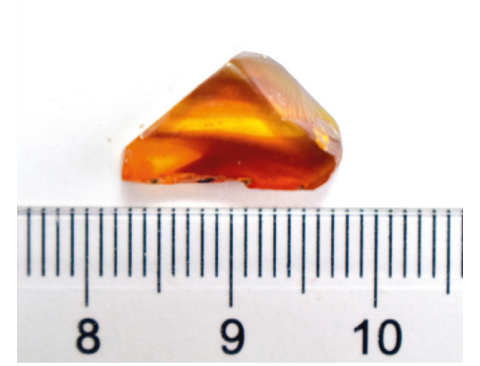

(b)

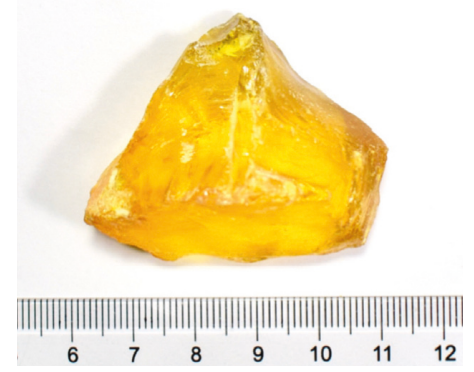

(e)

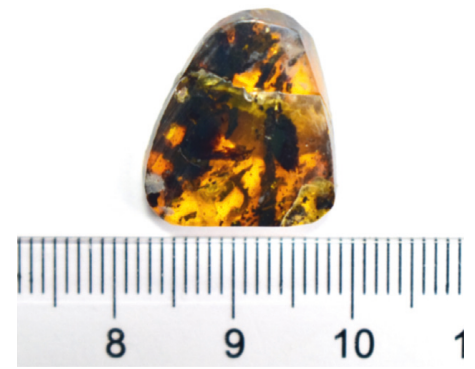

(c)

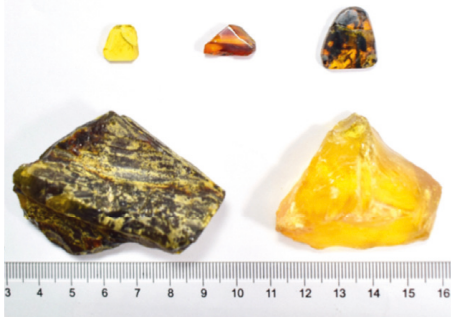

(f)

Figure 1: Photographs of experimental samples: (a) Burmese amber sample A-1; (b) Burmese amber sample A-2; (c) Burmese amber sample A-3; (d) copal sample (KB); (e) natural rosin sample (SX); (f) all specimens.

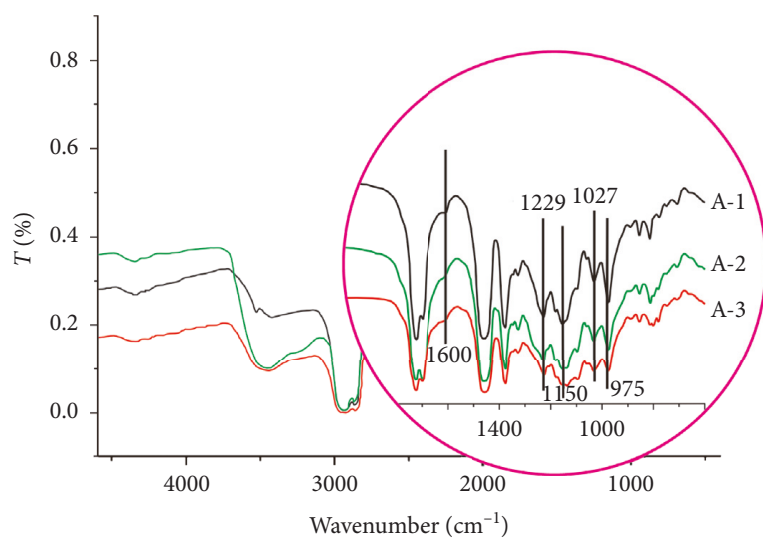

(a)

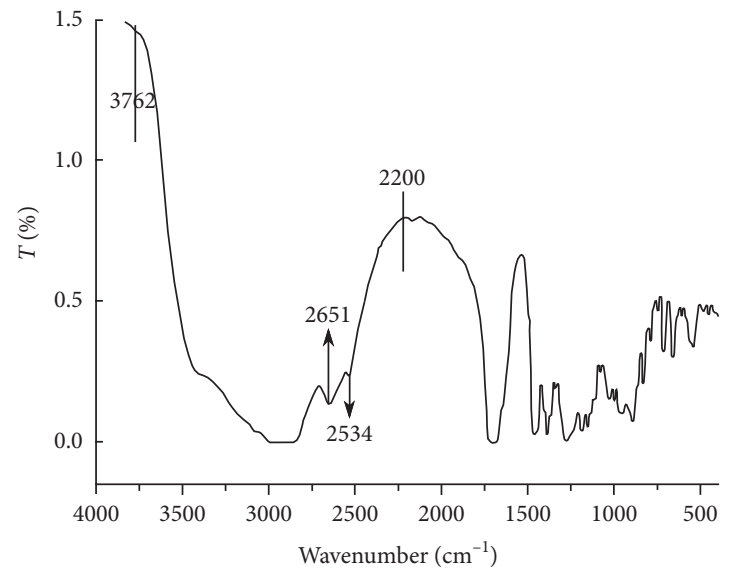

(c)

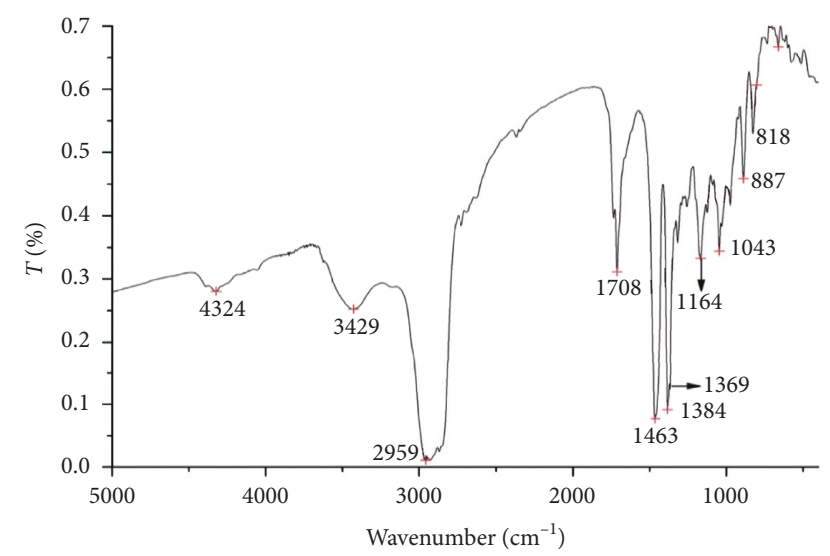

(b)

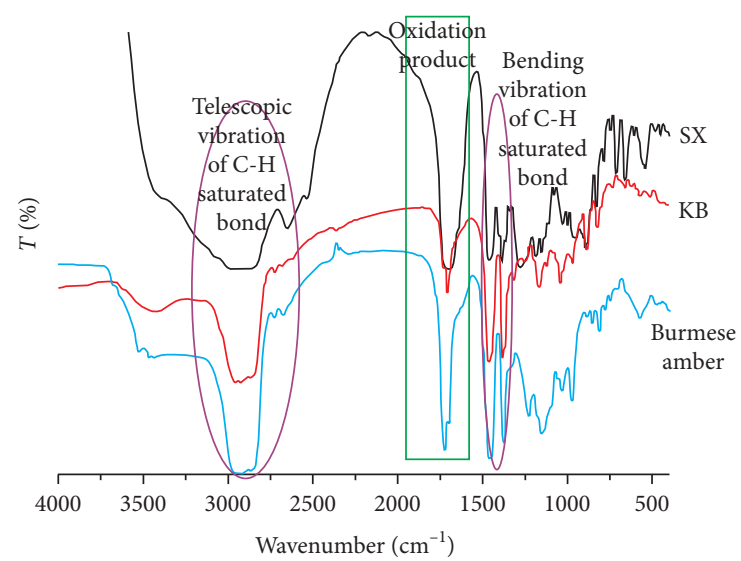

(d)

FIGURE 2: Infrared spectra of amber, copal, and rosin samples: (a) amber samples (A-1, A-2, and A-3); (b) copal sample (KB); (c) rosin sample (SX). (d) Comparison of amber, copal, and rosin (the amber spectrum shown in the average of the three amber samples). 
TABLE 1: Infrared peak attributions of the samples.

\begin{tabular}{|c|c|c|c|c|c|}
\hline \multirow[b]{2}{*}{ Group } & \multirow{2}{*}{$\begin{array}{l}\text { Saturated or } \\
\text { unsaturated }\end{array}$} & \multicolumn{3}{|c|}{ Infrared peak position $\left(\mathrm{cm}^{-1}\right)$} & \multirow[b]{2}{*}{ Evolution of spectral feature } \\
\hline & & $\begin{array}{l}\text { Burmese } \\
\text { ambers }\end{array}$ & Copal & Rosin & \\
\hline $\mathrm{CH}_{2}, \mathrm{CH}_{3}$ & Saturated & $\begin{array}{c}2925,2866,2847,1458 \\
1375\end{array}$ & $\begin{array}{c}2957,2869,1464 \\
1384\end{array}$ & 1466,1389 & $\begin{array}{l}\text { Diminishing absorption intensity from } \\
\text { Burmese amber to copal to rosin }\end{array}$ \\
\hline & & & & & $\begin{array}{l}\text { Decreasing absorption intensity from } \\
\text { Burmese amber to copal to rosin. }\end{array}$ \\
\hline$v\left(\mathrm{CH}_{2}-\mathrm{CH}_{3}\right)$ & Saturated & 2731,2672 & 2728,2670 & 2724,2667 & $\begin{array}{l}\text { Hydrogen bond cleavage during the } \\
\text { formation of amber forms a stable } \\
\text { saturated hydrocarbon structure. }\end{array}$ \\
\hline $\mathrm{C}=\mathrm{O}$ & Unsaturated & $1719-1724$ & $1720-1726$ & $1710-1722$ & $\begin{array}{c}\text { The peak is split in the spectra of } \\
\text { the amber samples. }\end{array}$ \\
\hline $\begin{array}{l}\text { Unsaturated } \\
\text { six-membered ring }\end{array}$ & Unsaturated & 1600 & - & - & $\begin{array}{l}\text { Weak absorption in spectra of amber } \\
\text { samples }\end{array}$ \\
\hline Isopropyl & Saturated & 1383 & 1384,1369 & 1372,1386 & $\begin{array}{l}\text { Diminishing absorption intensity } \\
\text { from Burmese amber to copal to rosin }\end{array}$ \\
\hline Isopropyl skeleton & Saturated & 1162 & 1164 & 1161 & $\begin{array}{l}\text { The absorption intensity of Burmese } \\
\text { amber, } \\
\text { copal, and rosin is almost the same }\end{array}$ \\
\hline $\begin{array}{l}\text { Intramolecular } \\
\text { hydrogen } \\
\text { bonding between } \\
\text { carboxylic acids }\end{array}$ & Saturated & - & - & 2651,2534 & $\begin{array}{l}\text { No absorption peaks are seen } \\
\text { in the spectra of copal and amber. }\end{array}$ \\
\hline $\begin{array}{l}\text { Trans-structure, } \\
\text { hydroxy group }\end{array}$ & - & 975 & 975 & - & - \\
\hline
\end{tabular}

from external matter and environmental factors. For example, the presence of the $\mathrm{O}-\mathrm{H}$ stretching band (broadband centered at $3450 \mathrm{~cm}^{-1}$ ) is common in $\mathrm{KBr}$ tablets; therefore, it is difficult to determine whether it is $\mathrm{H}_{2} \mathrm{O}$ contained in the samples. According to the position of the polymer between 2000 and $600 \mathrm{~cm}^{-1}$, groups can be categorized, for example, $1800-1700 \mathrm{~cm}^{-1}$ can indicate groups containing ester carboxylic acid and $1500-1300 \mathrm{~cm}^{-1}$ can indicate saturated linear aliphatic groups and polyolefin substituted by polar groups [19]. Vibration types and strength of different samples are different; therefore, the second strong band can be used as the classification basis for the samples.

In the spectra of all three amber samples (Figure 2(a)), the second strong absorption band is located in the region of $1500-1300 \mathrm{~cm}^{-1}$. The polymers in these samples are mainly saturated linear aliphatic polyolefins, potentially containing polar substituents. The absorption peak of carbonyl is located in the range of $1660-1740 \mathrm{~cm}^{-1}$; however, the absorption peak is split, indicating that the unsaturated carbonyl double-bond structure is cleaved continuously, and it crosslinks with other unsaturated structures to form a larger saturated molecular structure during the petrification process. In the infrared spectrum of copal (Figure 2(b)), the second strong band is located around $1458 \mathrm{~cm}^{-1}$, and the polymer species are mainly saturated linear aliphatics and polyolefins substituted with polar groups [19]. In the infrared spectrum of rosin (Figure 2(c)), the second strong band is located around $1720 \mathrm{~cm}^{-1}$, and the primary polymers contain ester and carboxylic acid groups [19].

The infrared spectra of rosin, copal, and amber are comparatively analyzed in Figure $2(\mathrm{~d})$. The peaks at $2651 \mathrm{~cm}^{-1}$ and $2534 \mathrm{~cm}^{-1}$, which correspond to intramolecular hydrogen bonding between carboxylic acids, were observed only in the spectrum of rosin. Thus, during the polymerization of rosin to copal, the interaction between carboxylic acids in the acidic resin becomes weak or disappears. Rosin is an acidic resin containing a large amount of resin acid. Burmese amber and copal have sharp absorption peaks at $975 \mathrm{~cm}^{-1}$, which correspond to the out-of-plane bending vibration caused by the trans-structure in the conjugated system or the out-of-plane deformation vibration of the hydroxyl group. Broad infrared absorption bands are also observed in the range of $2200-3759 \mathrm{~cm}^{-1}$; these characteristic peaks of amber and copal are not present in the infrared spectrum of rosin.

During the process of structural polymerization from rosin to copal to amber, the absorption of saturated hydrocarbon groups (i.e., methyl and methylene; stretching vibration around $2960 \mathrm{~cm}^{-1}, 2870 \mathrm{~cm}^{-1}, 2920 \mathrm{~cm}^{-1}$, and $2850 \mathrm{~cm}^{-1}$; bending vibration near $1460 \mathrm{~cm}^{-1}$ and $1380 \mathrm{~cm}^{-1}$ ) is gradually strengthened. During the long geological process by which copal is transformed into amber, the volatile components are gradually lost, and the soluble components are reduced. Simultaneously, oxidation is gradually enhanced, and the absorption of the oxidation product, which is observed at $1680-1750 \mathrm{~cm}^{-1}$, is also enhanced (Figure 2(d)).

3.2. Raman Spectroscopy. The Raman spectra of all samples are shown in Figure 3. The vibration of the benzene ring has Raman activity, while the vibrations of hydrocarbon and carbonyl groups have infrared activity. Thus, while the infrared spectrum characterizes the functional groups, the Raman spectrum provides information about the vibration of the core molecular structure. In this study, the Raman 


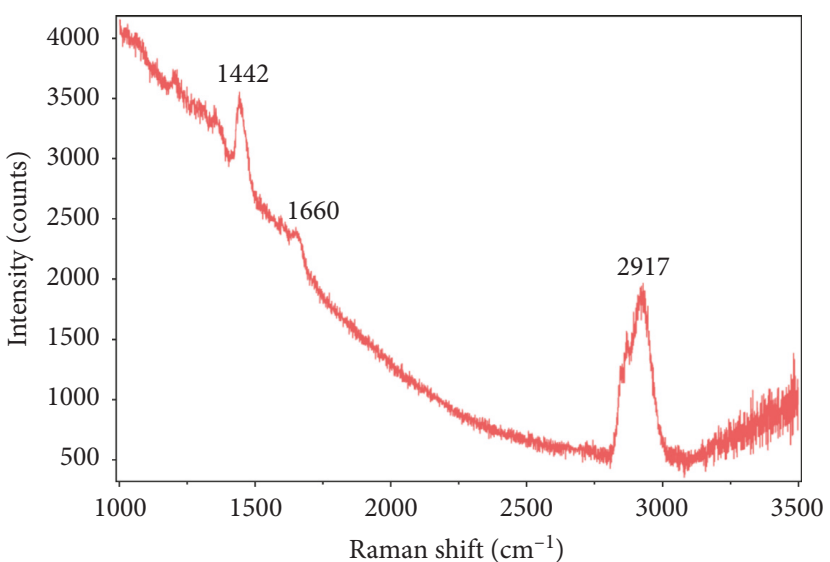

A-1

(a)

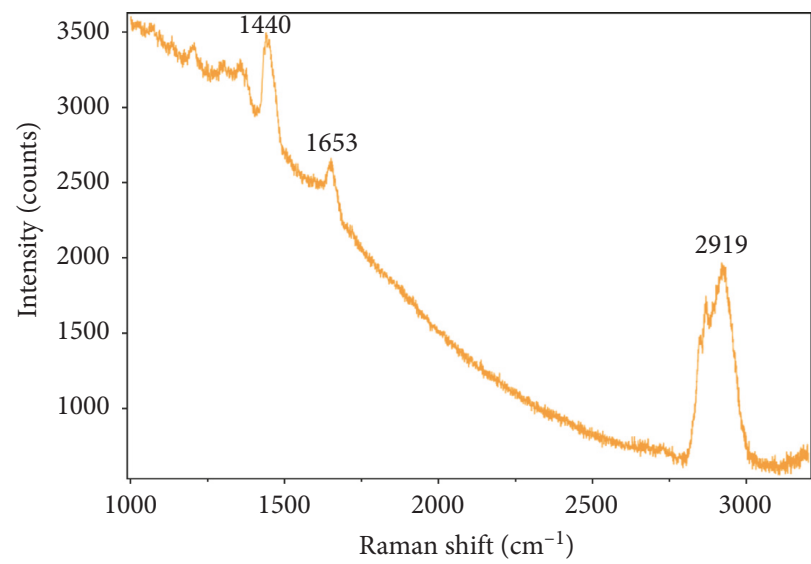

A-3

(c)

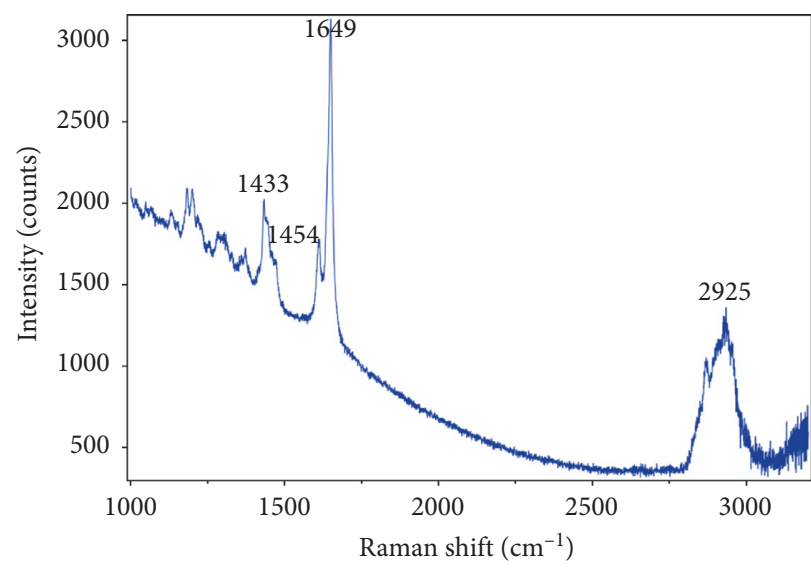

SX

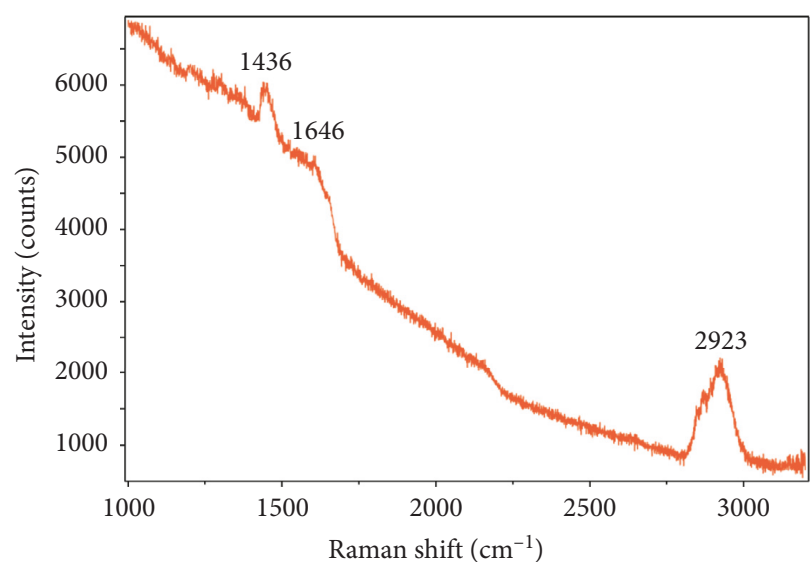

A-2

(b)

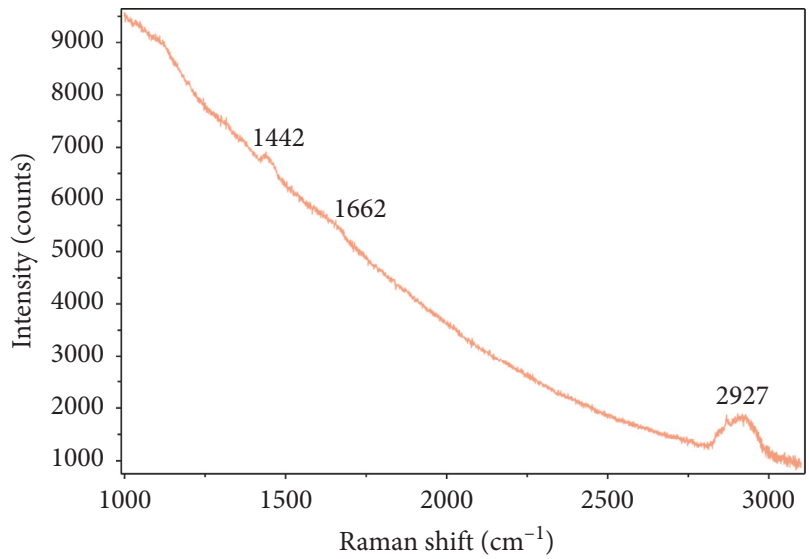

$\mathrm{KB}$

(d)

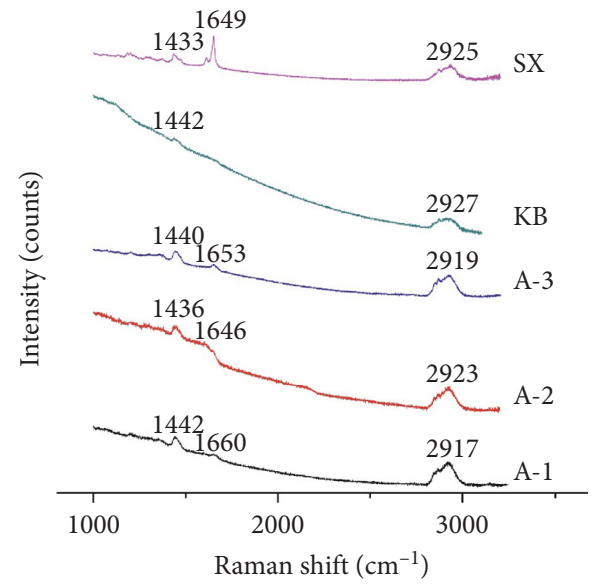

(f)

FIgURE 3: Raman spectra of amber, copal, and rosin samples. Burmese amber samples: (a) A-1, (b) A-2, and (c) A-3. (d) Copal sample (KB). (e) Rosin sample (SX). (f) All samples.

spectra revealed significant fluorescence background in all samples along with significant baseline drift in the measured Raman line. The Raman peak positions of the samples are shown in Table 2.
The absorption peaks and corresponding functional groups observed in the Raman spectra are summarized as follows (Figure 3(f)): saturated hydrocarbyl $\mathrm{CH}_{2}$ absorption at $2917 \mathrm{~cm}^{-1}$ (A-1), $2923 \mathrm{~cm}^{-1}$ (A-2), $2919 \mathrm{~cm}^{-1}$ (A-3), $2927 \mathrm{~cm}^{-1}$ 
TABLE 2: Raman peak attributions of the amber, copal, and rosin samples.

\begin{tabular}{|c|c|c|c|c|c|c|c|}
\hline \multirow{3}{*}{ Group } & \multirow{3}{*}{$\begin{array}{l}\text { Saturated or } \\
\text { unsaturated }\end{array}$} & \multicolumn{5}{|c|}{ Raman peak $\left(\mathrm{cm}^{-1}\right)$} & \multirow{3}{*}{$\begin{array}{c}\text { Evolution of spectral } \\
\text { feature }\end{array}$} \\
\hline & & \multicolumn{3}{|c|}{ Burmese amber } & \multirow{2}{*}{ Copal } & \multirow{2}{*}{ Rosin } & \\
\hline & & A-1 & A-2 & A-3 & & & \\
\hline $\begin{array}{l}\text { Conjugated unsaturated } \\
\text { double bond in carbon } \\
\text { chain skeleton } \mathrm{C}=\mathrm{C}\end{array}$ & Unsaturated & 1660 & 1646 & 1653 & 1662 & 1649 & $\begin{array}{c}\text { The peak intensity } \\
\text { differs between amber and } \\
\text { copal/rosin }\end{array}$ \\
\hline $\begin{array}{l}\text { Saturated hydrocarbon } \\
\text { group } \mathrm{CH}_{2}\end{array}$ & Saturated & 2917 & 2923 & 2919 & 2927 & 2925 & - \\
\hline $\begin{array}{l}\text { Carbon-carbon single } \\
\text { bond } \mathrm{C}-\mathrm{C} \text { in carbon } \\
\text { chain skeleton }\end{array}$ & Saturated & 1442 & 1436 & 1440 & 1442 & 1433 & - \\
\hline
\end{tabular}

(copal), and $2925 \mathrm{~cm}^{-1}$ (rosin); conjugated unsaturated double bond $(C=C)$ absorption at $1660 \mathrm{~cm}^{-1}(\mathrm{~A}-1), 1646 \mathrm{~cm}^{-1}(\mathrm{~A}-2)$, $1653 \mathrm{~cm}^{-1}$ (A-3), $1662 \mathrm{~cm}^{-1}$ (copal), and $1649 \mathrm{~cm}^{-1}$ (rosin); and $\mathrm{C}-\mathrm{C}$ nonpolar vibration in the carbon chain skeleton at $1442 \mathrm{~cm}^{-1}$ (A-1), $1436 \mathrm{~cm}^{-1}$ (A-2), $1440 \mathrm{~cm}^{-1}$ (A-3), $1442 \mathrm{~cm}^{-1}$ (copal), and $1433 \mathrm{~cm}^{-1}$ (rosin) [20]. Among the samples, the absorption of conjugated unsaturated double bonds $(\mathrm{C}=\mathrm{C})$ in the carbon chain skeleton near $1660 \mathrm{~cm}^{-1}$ is the strongest for rosin, indicating that rosin has the highest $\mathrm{C}=\mathrm{C}$ content. In contrast, the $\mathrm{C}=\mathrm{C}$ contents are low in both copal and Burmese amber. The peaks corresponding to carbon-carbon single bonds $(\mathrm{C}-\mathrm{C})$ in the nonpolar vibration-saturated carbon chain skeleton $\left(1442 \mathrm{~cm}^{-1}, 1436 \mathrm{~cm}^{-1}\right.$, and $\left.1440 \mathrm{~cm}^{-1}\right)$ are strong in the amber spectra. Conversely, the peaks at $1442 \mathrm{~cm}^{-1}$ in the copal spectrum and $1433 \mathrm{~cm}^{-1}$ in the rosin spectrum are weak (Table 2). These findings indicate that the unsaturated conjugated bond structure $(\mathrm{C}=\mathrm{C})$ is continually broken, and the nonpolar vibration-saturated carbon-carbon single bond structure $(\mathrm{C}-\mathrm{C})$ is gradually increased during the conversion from rosin to copal and amber.

3.3. UV-Vis Spectroscopy. The UV absorption spectrum provides information on conjugated systems and some carbonyl groups [21]. In this study, the UV-Vis spectra of Burmese amber, copal, and rosin were analyzed in two absorption regions: the visible light region from 400$760 \mathrm{~nm}$ and the UV region from 200-400 nm. Key differences were observed between the spectra of the different samples. In the visible light region, the absorption of amber sample A-1 is located in the blue-violet region at 400$480 \mathrm{~nm}$ (Figure 4(a)); thus, sample A-1 exhibits a yellow color. In the UV region, sample A-1 shows absorption at $252 \mathrm{~nm}$ and $211 \mathrm{~nm}$, which are assigned to carbonyl absorption and unsaturated conjugated double bond structure absorption, respectively. These results indicate the presence of an unsaturated carbonyl group and a conjugated double-bond structure in sample A-1. There absorption curve around $300 \mathrm{~nm}$ and $395 \mathrm{~nm}$ includes two inflection points, and the positions of the inflection points are directly related to the color of the sample.

The absorption of amber sample A-2 in the range of $200-500 \mathrm{~nm}$ is rather disordered (Figure 4(b)). The absorption curve of sample A-2 shows an inflection point at $512 \mathrm{~nm}$. Compared to sample A-1, the wavelength corresponding to the sudden decrease in absorption exhibited a bathochromic shift, consistent with the darker color of sample A-2. These results indicate an increased concentration of carbonyl groups that help deepen colors during the formation process. These findings are consistent with those of Rao et al. [12], who reported that the inflection point in the absorbance curve of natural amber appears near $450 \mathrm{~nm}$ because the inflection point of the amber UV curve differs based on the color depth of the sample. Sample A-2 also showed absorption in the range of $500-560 \mathrm{~nm}$, so the sample exhibited a red-brown color.

Due to the poor transparency of sample A-3, reflection spectroscopy was used to collect the UV-Vis spectrum (Figure 4(c)). Sample A-3 exhibited absorption in the range of 400-720 nm; thus, sample A-3 absorbed most light in the visible region, resulting in a dark (black) color. Sample A-3 also showed strong absorption at $255 \mathrm{~nm}$ and $215.5 \mathrm{~nm}$, indicating that unsaturated carbonyl groups and conjugated double-bond structures remained in this sample. A charge transfer at $727 \mathrm{~nm}$ was observed and assigned to $\mathrm{Fe}^{2+}$. Fan et al. [22] found that the absorption of tourmaline at $718 \mathrm{~nm}$ was caused by the charge transition of $\mathrm{Fe}^{3+}$, and Hou et al. [23] reported that the broadband of tourmaline centered at $720 \mathrm{~nm}$ (or nearby) was caused by $\mathrm{Fe}^{2+}$. Thus, the absorption of sample A-3 near $727 \mathrm{~nm}$ is directly related to iron-containing inclusions such as pyrite.

Copal (KB) absorbs significantly in the visible region from 400 to $560 \mathrm{~nm}$, with stronger absorption of blue-green light (Figure 4(d)). Therefore, the color of copal is dark yellowish-brown color. In the UV region (200-400 nm), copal shows obvious absorption at $263 \mathrm{~nm}$ and $215 \mathrm{~nm}$, corresponding to carbonyl groups and an unsaturated, conjugated double-bond structure, respectively.

Rosin (SX) absorbs violet-blue light in the region of 400-500 nm (Figure 4(e)), resulting in a yellow hue in this sample. In the UV region (200-400 nm), the absorption of rosin is very gentle, and no obvious absorption peak is observed. This indicates the presence of unsaturated bonds in the structure of rosin.

3.4. Solubility in Organic Solvents. To investigate changes in solubility during amber formation, rosin, copal, and Burmese amber powders were separately placed in six different organic solvents: ethanol, acetone, 1,4-dioxane, ethylacetate, 


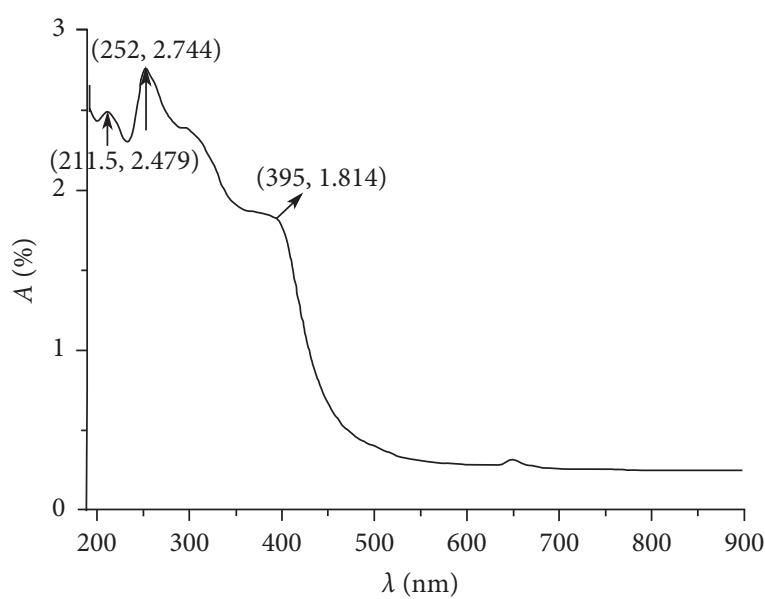

(a)

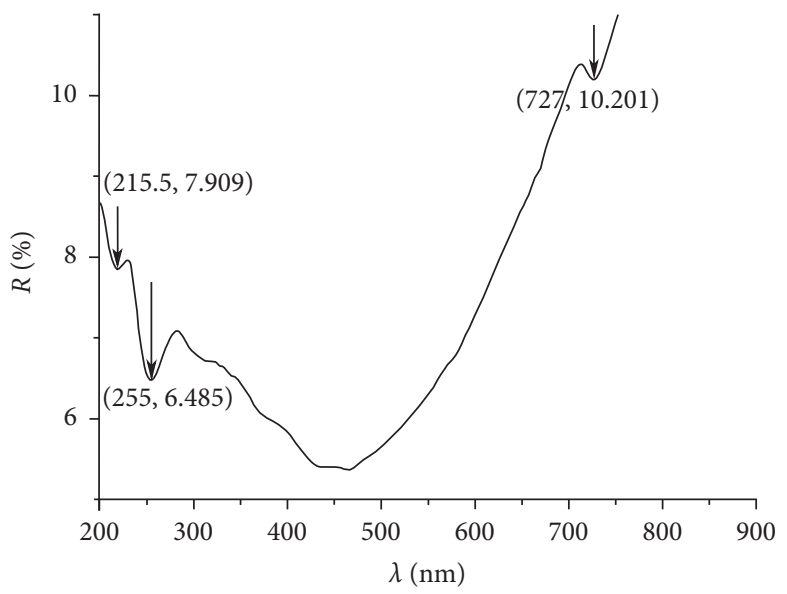

(c)

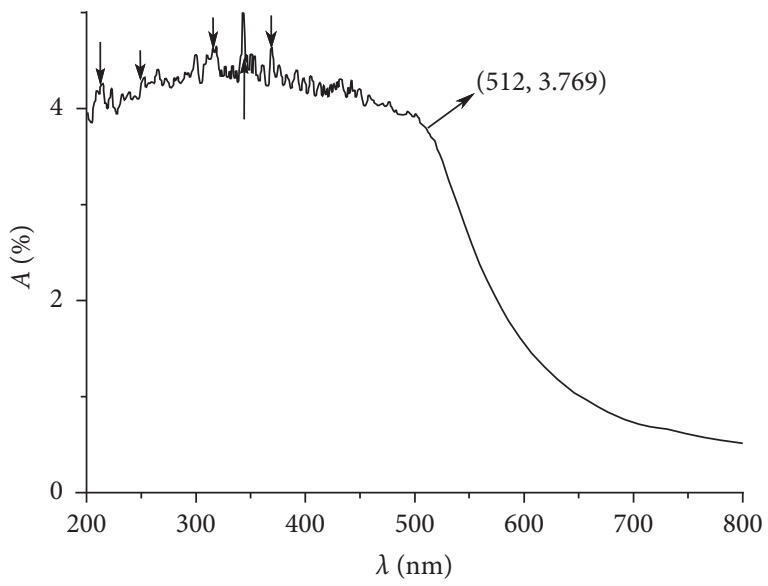

(b)

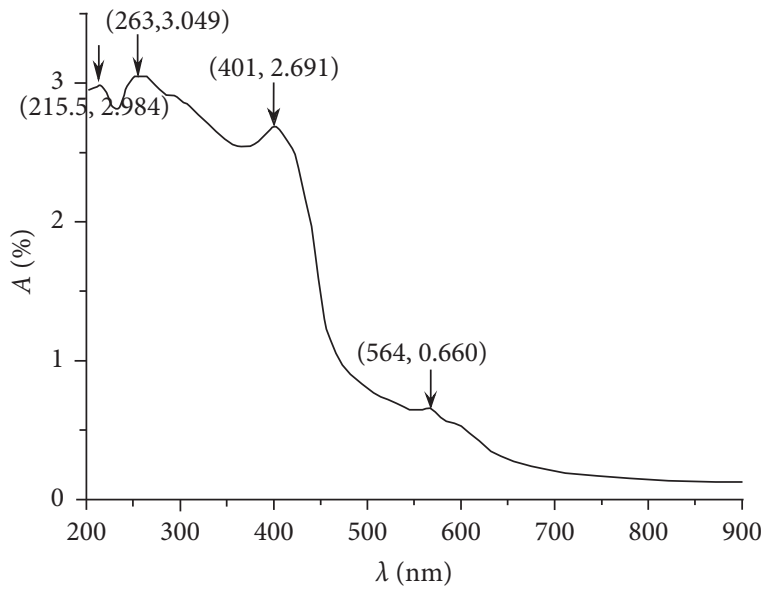

(d)

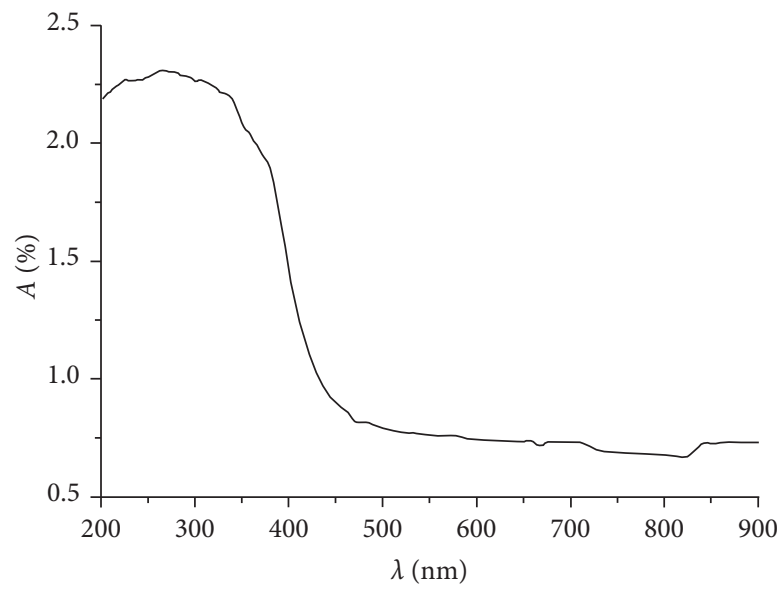

(e)

FIGURE 4: UV-Vis spectra of amber, copal, and rosin samples. Burmese amber samples: (a) A-1, (b) A-2, and (c) A-3. (d) Copal sample (KB). (e) Rosin sample (SX).

$\mathrm{N}, \mathrm{N}$-dimethylamide, and dichloromethane. The polarity and solubility of each sample were then evaluated according to the principle of similar compatibility. The experimental results are shown in Table 3.

The experimental results (Table 3 ) suggest that rosin was completely dissolved in the six solvents, whereas Burmese amber was insoluble or poorly soluble. The solubility of copal was in between rosin and Burmese amber. Thus, solubility $(S)$ decreased in the order of $S_{\text {rosin }}>S_{\text {copal }}>$ $S_{\text {Burmeseamber. }}$ Copal was substantially dissolved in dichloromethane, which may be related to the polarity imparted by chloride ions. Rosin is a lipid-based substance 
TABLE 3: Solubilities of amber, copal, and rosin samples in organic solvents.

\begin{tabular}{lcccccc}
\hline Sample & Ethanol & Acetone & Dichloromethane & $\begin{array}{c}\text { Organic solvent } \\
\text { Dioxane }\end{array}$ & Ethylacetate & $\begin{array}{c}\text { N,N- } \\
\text { Dimethylamide } \\
\text { (DMF) }\end{array}$ \\
\hline $\begin{array}{l}\text { Burmese } \\
\text { amber }\end{array}$ & IN & IN & IN & IN & IN & IN \\
Copal & PD & PD & DI & PD & PD & PD \\
Rosin & CD & CD & CD & CD & CD & CD \\
\hline
\end{tabular}

$\mathrm{IN}=$ insoluble; $\mathrm{DI}=$ dissolved; $\mathrm{PD}=$ partially dissolved; $\mathrm{CD}=$ completely dissolved .

with low polarity that is easily soluble in organic solvents. The degrees of oxidation of copal and Burmese amber along with the adhesion of carbon-carbon double bonds increase with age. Thus, as age increases, the molecules become larger and more stable, making them more difficult to dissolve in organic solvents. In the petrifaction process, amber undergoes a qualitative change in solubility, and the amount of soluble components within amber decreases. The physical properties of amber also change along with the chemical properties.

\section{Discussion}

4.1. Spectral Characteristics Indicate the Structures of Rosin, Copal, and Amber. As mentioned above, the second strong infrared band of rosin is located at $1800-1700 \mathrm{~cm}^{-1}$, indicating that the rosin molecule mainly contains carbonyl groups. In copal and Burmese amber, the second strong infrared absorption bands are located in the range of $1500-1300 \mathrm{~cm}^{-1}$. The main polymers in these samples are saturated linear aliphatic polyolefins, potentially containing polar substituents. The spectroscopic results indicate that over geological time, the unsaturated bonds are broken and gradually polymerized into a chain structure. Abduriyim et al. [24] and Wang et al. [14] concluded that during the conversion from resin to amber, the basic constituent labdanoid diterpenes are crosslinked to form a three-dimensional polymer chain structure. Lambert et al. [9] presented a simplified scheme for the formation of amber (Figure 5).

During the long petrifaction process, the degree of polymerization of the petrified resin increases, unsaturated double bonds are broken through polymerization, and the labdanoid diterpene molecules crosslink to form chain polymers with certain spatial configurations. As a result, the relative intensity of the Raman peak at $1760-1540 \mathrm{~cm}^{-1}$ gradually weakens during petrifaction, whereas the intensity of the peak at $1530-1400 \mathrm{~cm}^{-1}$ is enhanced. Therefore, the relative strengths of these two vibration peaks can be used to determine the extent of petrifaction. The ratio of the areas of these two peaks $(N)$ were determined as $N=S 1 / S 2$, where $S 1$ is the area of vibration peak in the wavenumber range of $1760-1540 \mathrm{~cm}^{-1}$ and $S 2$ is the area of the vibration peak in the range of $1530-1400 \mathrm{~cm}^{-1}$ ). The calculated values of $N_{\mathrm{A}-1}, N_{\mathrm{A}-2}$, $N_{\mathrm{A}-3}, N_{\mathrm{KB}}$, and $N_{\mathrm{SX}}$ were $1.28,1.31,1.34,1.42$, and 1.53, respectively. The average value of $N$ for the Burmese ambers samples was 1.31. A smaller $N$ indicates a higher degree of polymerization. Thus, the degree of polymerization decreased in the following order: Burmese amber $>$ copal $>$ rosin.
In the UV-Vis absorption spectrum, amber shows obvious absorption around $211 \mathrm{~nm}, 512 \mathrm{~nm}$, and $250 \mathrm{~nm}$. The positions and intensities of the UV-Vis absorption peaks of the different amber samples differ based on the sample color. The Burmese amber samples show obvious absorption in the $\mathrm{UV}$ region above $210 \mathrm{~nm}$. Thus, we can conclude that the amber molecules contain unsaturated, conjugated doublebond structures with $\pi \longrightarrow \pi^{*}$ transitions. All three Burmese amber samples exhibit strong absorption at $250 \mathrm{~nm}$ due to the presence of carbonyl groups, which is verified by the carbonyl peaks at $1720 \mathrm{~cm}^{-1}$ in the infrared spectra. The absorption intensity of these unsaturated conjugated double bonds is not large, indicating that Burmese amber is relatively mature and has relatively high saturation. Thus, we can conclude that no complex conjugated system is present in the amber molecules.

\subsection{Structural Fragments Present during Amber Formation.} Baltic amber emits a characteristic smell upon hand rubbing. This aroma is attributed to the volatile component $\beta$-myrcene $\left(\mathrm{C}_{10} \mathrm{H}_{16}\right)$, a naturally occurring monoterpenoid containing three double bonds, two of which are conjugated. $\beta$-myrcene aggregates easily after long periods of storage. Wang et al. [25] found that natural myrcene is present in the volatile oils of cupressaceae and rosaceous plants. However, most Burmese ambers do not contain aromatics. This difference is attributed to the different types of resins that Burmese amber and Baltic amber are formed from. Burmese amber is derived from the resin secreted by tropical legumes. Zong et al. [26] found that diterpenoids (e.g., rosin acid) are the main nonvolatile components in legume resin. The basic structure of a diterpenoid is shown in Figure 6.

Amber contains organic substances such as succinic acid and amber resin acid [27]. The specific components of amber vary depending on the place of origin. Lambert et al. [9] found that Burmese amber mainly contains Class Ib resin acids (Figure 7). Burmese amber is formed by long-term mineralization in a reduction environment. In amber, the resin acids with a low degree of petrifaction or poor maturity are easily replaced by retene compounds (Figure 8), resulting in decreased amber quality and increased brittleness. Most Burmese ambers can be processed and carved, indicating that few resin acids have been replaced by retenes and that the degree of amber petrifaction or maturity is high. After mining, amber is found in an oxidizing environment, causing its color. Fe in mined amber is oxidized, and the unsaturated bonds are broken to form stable oxygen-containing groups. 

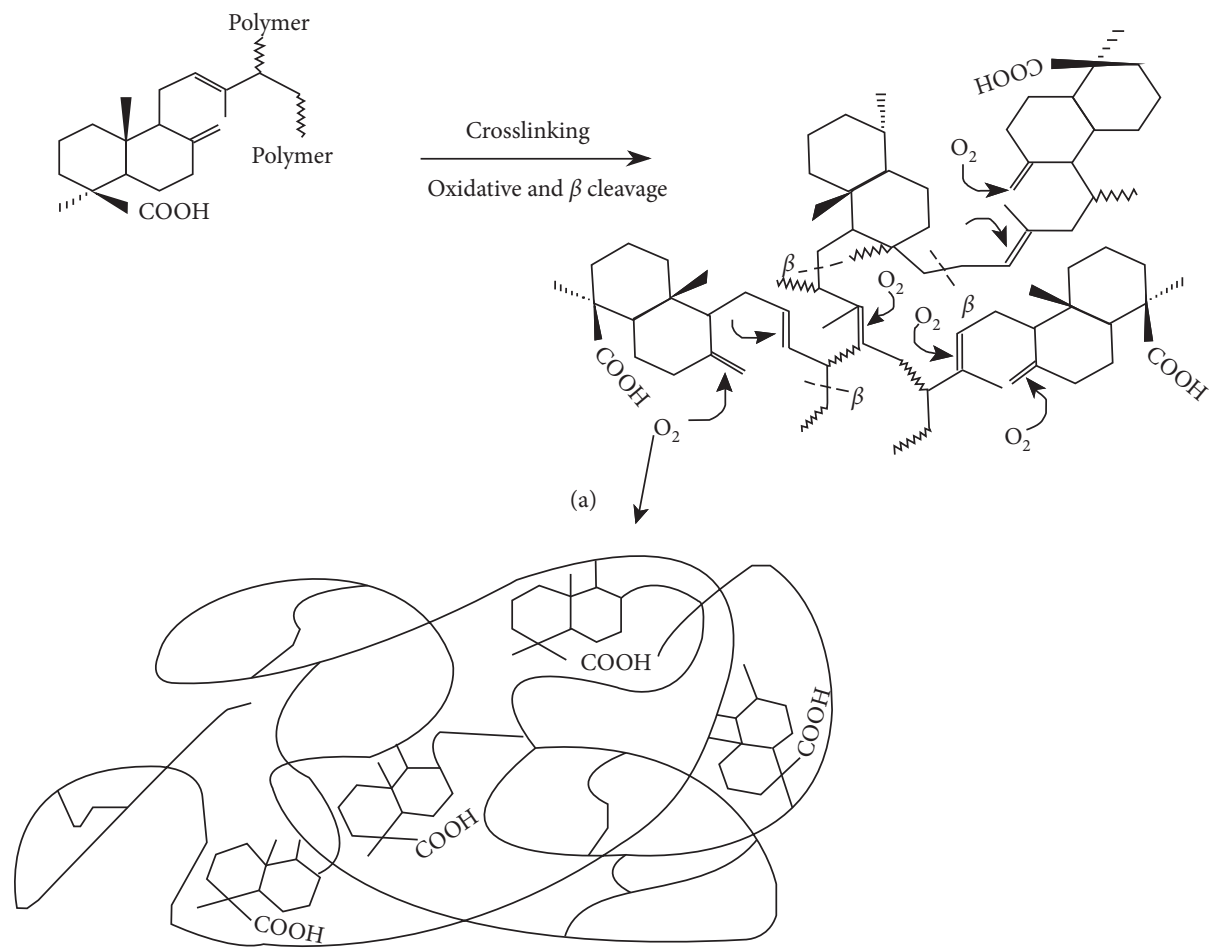

(b)

FIGURE 5: Amber formation via a crosslinking polymerization process (as proposed in [9]).<smiles>[R]COC(=O)O</smiles>

Figure 6: Structure of diterpenoid compounds.

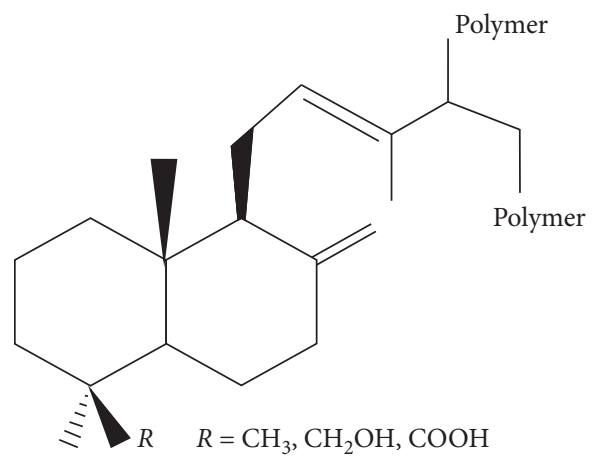

FIgURE 7: Class Ib resin structural unit.

4.3. Inference of Amber Formation Process by Spectral Analysis. The infrared spectrum of a polymer blend primarily characterizes the monomer structure in the main

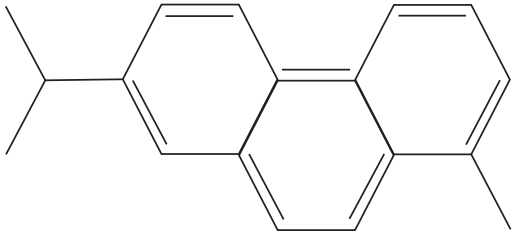

FIgURE 8: Structure of stilbene.

polymer component; it is difficult to detect the structures of minor components. Infrared, Raman, and UV-Vis spectroscopic analyses indicated the presence of unsaturated carbon-carbon double bonds, carbonyl groups, methyl groups, and methylene groups in the structures of copal and amber. Based on the structure of the resin from which Burmese amber formed, we can infer that the amber structure includes a closed six-membered ring. A benzene ring is formed if the six-membered ring contains three unsaturated bonds in interphase distribution. Burmese amber is the oldest known amber in terms of formation age. During the long geological process of amber formation, the unsaturated bond breakage should be adequate. Since the degree of type $\mathrm{Ib}$ resin substituted by retene is low, Burmese amber likely contains no or a very small amount of benzene rings. Moreover, the degree of unsaturation of diterpenoids is reduced after polymerization and reduction.

Based on the above analysis, the formation of amber from resin, which proceeds through the intermediate copal (i.e., semipetrified resin), is a long process that involves a series of complex chemical changes. Figure 9 shows the structural fragments and changes that occur during amber formation based on the experimental data. 

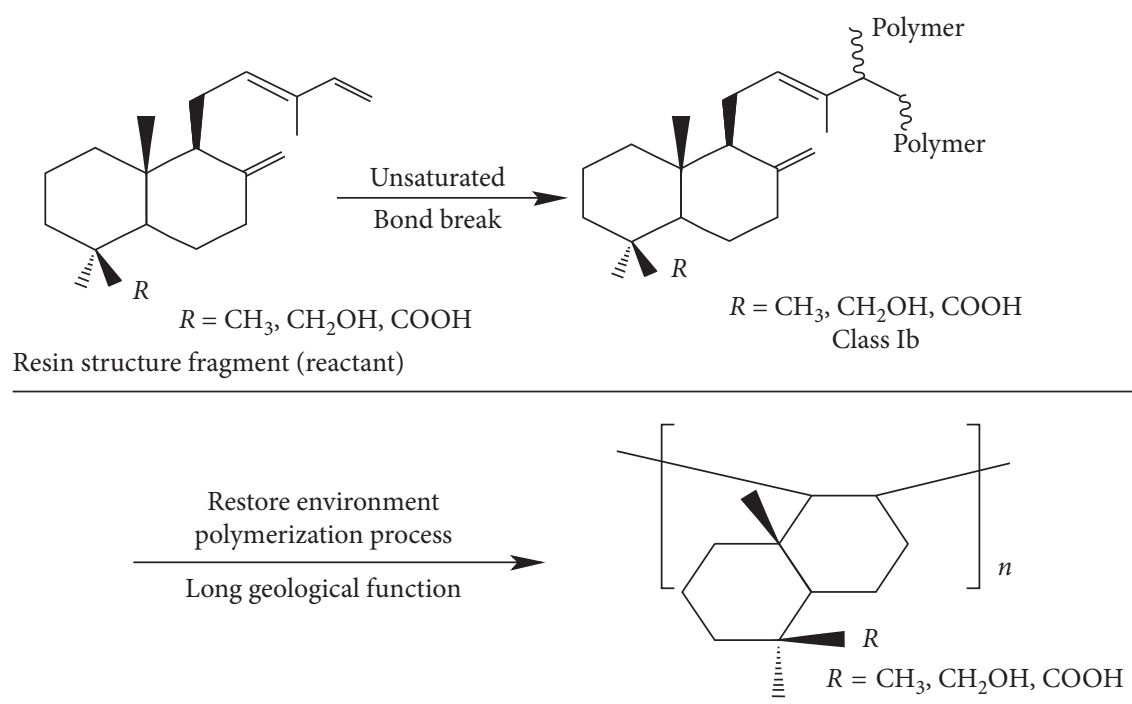

Postpolymerization structure fragment (intermediate product)
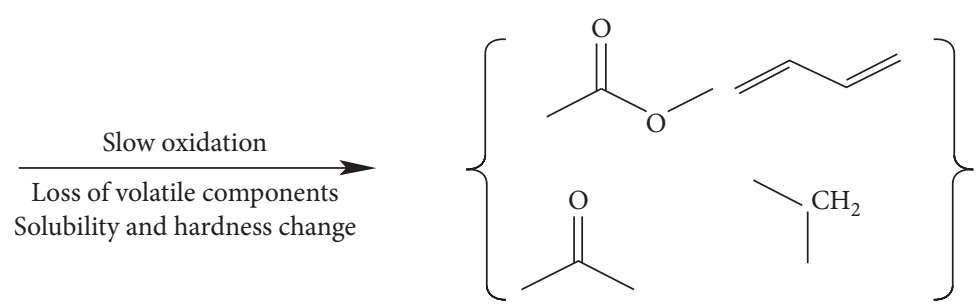

Burmese amber structure

fragment (final product)

FIgURE 9: Structural changes involved in the formation of Burmese amber.

During the formation of Burmese amber, the unsaturated bonds of nonvolatile diterpenoids (e.g., rosin acid) in the resin secreted by the original tropical legumes were broken, forming Class Ib resin acids in the amber. During the long geological process, the unsaturated bonds were continuously broken to form resin acids under reducing conditions and the resin acids undergo polymerization to form large, crosslinked organic molecules with six-membered ring structures. These crosslinked molecules finally formed a larger polymeric structure containing organic molecules with saturated hydrocarbon groups $\left(\mathrm{CH}_{2}\right.$ and $\left.\mathrm{CH}_{3}\right)$, unsaturated carbonyl groups $(\mathrm{C}=\mathrm{O})$, conjugated unsaturated double bonds $(\mathrm{C}=\mathrm{C})$, oxygensaturated single bonds $(\mathrm{C}-\mathrm{O})$ in the carbon chain, and nonpolar saturated carbon-carbon single bonds $(\mathrm{C}-\mathrm{C})$ in Burmese amber.

\section{Conclusion}

Based on infrared spectroscopy analysis, the absorption of saturated hydrocarbon groups (i.e., methyl and methylene) strengthened gradually as rosin polymerized to copal and then to amber. Simultaneously, the volatile components are gradually lost, and the quantity of soluble components is reduced as oxidation progresses during the transformation of copal to amber. During the formation of amber, the small molecules of the resin first undergo crosslinking polymerization, and a slow oxidation reaction occurs to form a stable organic polymer mixture. Raman spectroscopy analysis indicated that as the degree of polymerization and petrifaction in resin increases, unsaturated double bonds break, and labdanoid diterpene molecules crosslink to form chain polymers. These changes resulted in the gradual weakening and strengthening of the relative intensities of the peaks at $1760-1540 \mathrm{~cm}^{-1}$ and $1530-1400 \mathrm{~cm}^{-1}$, respectively, as rosin transformed to copal and then amber. Thus, among the samples, the degree of polymerization was largest in Burmese amber and smallest in rosin. The Raman and infrared spectroscopic results indicated that the structure of amber contains a six-membered ring. Absorption in the UV region (200-400 nm) indicated that Burmese amber, copal, and rosin contain unsaturated bonds (e.g., carbonyl groups) and conjugated systems. The structure of Burmese amber includes an unsaturated conjugated double bond with a $\pi \longrightarrow \pi^{*}$ transition level. In six organic solvents (ethanol, acetone, 1,4-dioxane, ethylacetate, DMF, and dichloromethane), the solubility decreased with increasing degree of petrifaction (i.e., $S_{\text {rosin }}>S_{\text {copal }}>S_{\text {Burmese amber }}$ ). As petrifaction progressed, the molecules of Burmese amber grew larger and became more stable, making it more difficult to dissolve them in organic solvents. The above analyses indicate that Burmese amber contains large organic molecules with six-membered rings, saturated 
hydrocarbon groups $\left(\mathrm{CH}_{2}\right.$ and $\left.\mathrm{CH}_{3}\right)$, unsaturated carbonyl groups $(\mathrm{C}=\mathrm{O})$, conjugated unsaturated double bonds $(\mathrm{C}=\mathrm{C})$, oxygen-saturated single bonds $(\mathrm{C}-\mathrm{O})$ in the carbon chain, and nonpolar saturated carbon-carbon single bonds $(\mathrm{C}-\mathrm{C})$.

\section{Data Availability}

The data used to support the findings of this study are available from the corresponding author upon request.

\section{Conflicts of Interest}

The authors declare that they have no conflicts of interest regarding the publication of this article.

\section{Acknowledgments}

The authors are grateful to Ouyang Zhaoxia's help and gifts related to sample collection. The authors also thank the Beijing CUG Gem Testing Center for help with infrared spectroscopy and sample testing, Shi Wei for guidance and assistance in infrared spectroscopy analysis, and Dr. Liu Kairui from the Dalian Institute of Chemical Physics, Chinese Academy of Sciences, for guidance and assistance in solubility testing.

\section{References}

[1] B. Z. Yan, W. X. Li, and S. K. Jiao, "NMR study of resin acid isomers in disproportionated rosin," Chinese Journal of Magnetic Resonance, vol. 16, no. 5, pp. 449-453, 1999.

[2] M. X. Chen, Z. D. Zhao, Y. Gu et al., "Study on thermal variation rule of pimaric-type acid in rosin," Chemistry and Industry of Forest Products, vol. 29, no. 2, pp. 33-36, 2009.

[3] J. B. Lambert and J. S. Frye, "Carbon functionalities in amber," Science, vol. 217, no. 2, pp. 55-57, 1982.

[4] L. J. Qi, Z. Y. Zhou, G. L. Liao et al., "Polymerization behavior and 13C NMR representation of creen copal resins under heat-pressurized process," Journal of Gems and Gemology, vol. 12, no. 3, pp. 9-13, 2010.

[5] C. W. Beck, E. Wilbur, and S. Meret, "Infra-red spectra and the origin of amber," Nature, vol. 201, no. 4916, pp. 256-257, 1964.

[6] K. J. Vandenberg, J. Ossebaar, and H. vanKeulen, Analysis of Copal Resins in 19th Century Oil Paints and Resin/Oil Varnishes, P. van Grieken, K. Janssens, L. Van't dack's, and G. Meersman, Eds., Art, Antwerp, Belgium, 2002.

[7] G. H. Shi and R. Zhang, "Geological and gemological features and age constraint of the burmese amber," in Proceedings of the China Jewelry Academic Exchange Conference, pp. 56-59, Beijing, China, 2012.

[8] J. F. Yang, X. P. Dong, L. Guo et al., "Progress in chemical research of amber," Beijing Chinese Medicine, vol. 8, no. 21, pp. $245-347,2002$.

[9] J. B. Lambert, J. A. Santiago-Blay, and K. B. Anderson, "Chemical signatures of fossilized resins and recent plant exudates," Angewandte Chemie International Edition, vol. 47, no. 50, pp. 9608-9616, 2008.

[10] M. Guiliano, L. Asia, G. Onoratini, and G. Mille, "Applications of diamond crystal ATR FTIR spectroscopy to the characterization of ambers," Spectrochimica Acta Part A:
Molecular and Biomolecular Spectroscopy, vol. 67, no. 5, pp. 1407-1411, 2007.

[11] Y. M. Wang, M. X. Yang, and P. Niu, "Analysis on organic elements and content variation of ambers, treated ambers and copals from different producing areas around the world," Journal of Gems \& Gemmology, vol. 16, no. 2, pp. 10-17, 2014.

[12] Z. F. Rao, J. Xie, and K. Dong, "Spectroscopy characteristics of amber, copal resin and rosin," Chinese Journal of Spectroscopy Laboratory, vol. 30, no. 2, pp. 720-724, 2013.

[13] Y. P. Yang and Y. M. Wang, "Summary on organic components and relevant spectral characteristics of amber and copal," Journal of Gems \& Gemmology, vol. 12, no. 1, pp. 16-22, 2010.

[14] Y. Wang, W. Z. Jiang, X. Y. Chen et al., "Gemological characteristics and infrared absorption spectra of amber and its imitation," Shanghai Land \& Resources, vol. 2, no. 2, pp. 58-62, 2010.

[15] Y. J. Dong and X. Y. Yu, "Gemological and infrared spectroscopic characteristics of amber from several different Localities," in Proceedings of the China Jewelry Academic Exchange Conference, pp. 132-134, Beijing, China, July 2013.

[16] Y. M. Wang, M. X. Yang, and T. You, "Latest progress of pressed amber," Journal of Gems \& Gemmology, vol. 14, no. 1, pp. 38-45, 2012.

[17] G. Z. Peng and L. Zhu, "Ambers from Dominica republic," Journal of Gems \& Gemmology, vol. 8, no. 3, pp. 32-35, 2006.

[18] H. Y. Xu, "Infrared spectroscopy and spectral peak assignment of amber and its imitations," Master's thesis, Tongji University, Shanghai, China, 2007.

[19] Q. Xue, Spectroscopic Methods in the Study of Organic and Polymeric Compounds, Science Press, Beijing, China, 2011.

[20] H. S. Wang, "A study on Raman spectra and fluoremetry of the amber," Journal of Mineralogy and Petrology, vol. 11, no. 2, pp. 80-84, 1991.

[21] Y. C. Ning, Structural Identification of Organic Compounds and Organic Populology, Science Press, Beijing, China, 2nd edition, 2006.

[22] J. L. Fan, X. Q. Feng, S. G. Guo et al., "Specific optical absorption spectrum of tourmaline," Journal of the Chinese Ceramic Society, vol. 37, no. 4, pp. 523-530, 2009.

[23] Y. J. Hou, H. L. Hong, H. J. Xue et al., "Gemmological and mineralogical characteristics of coloured tourmaline from minas gerais state, Brazil," Journal of Gems \& Gemmology, vol. 10, no. 3, pp. 8-11, 2008.

[24] A. Abduriyim, H. Kimura, Y. Yokoyama et al., "Characterization of "green amber" with infrared and nuclear magnetic resonance spectroscopy," Gems \& Gemology, vol. 45, no. 3, pp. 158-177, 2009.

[25] J. E. Wang, Y. L. Zhu, and C. J. Xiong, "Sources and application in perfume chemistry of myrcene," Shandong Chemical Industry, vol. 40, no. 3, pp. 47-50, 2011.

[26] P. Zong, J. Z. Xue, and B. Tang, "Tracing the most ancient amber: the origin and evolution of resin-producing plants," Acta Petrologica Et Mineralogica, vol. 33, pp. 111-116, 2014.

[27] B. L. Zhang, System Gemology, Geological Publishing House, Beijing, China, 2006. 

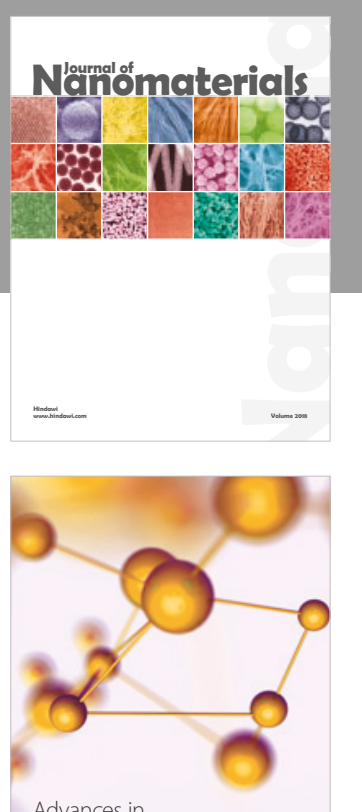

Physical Chemistry
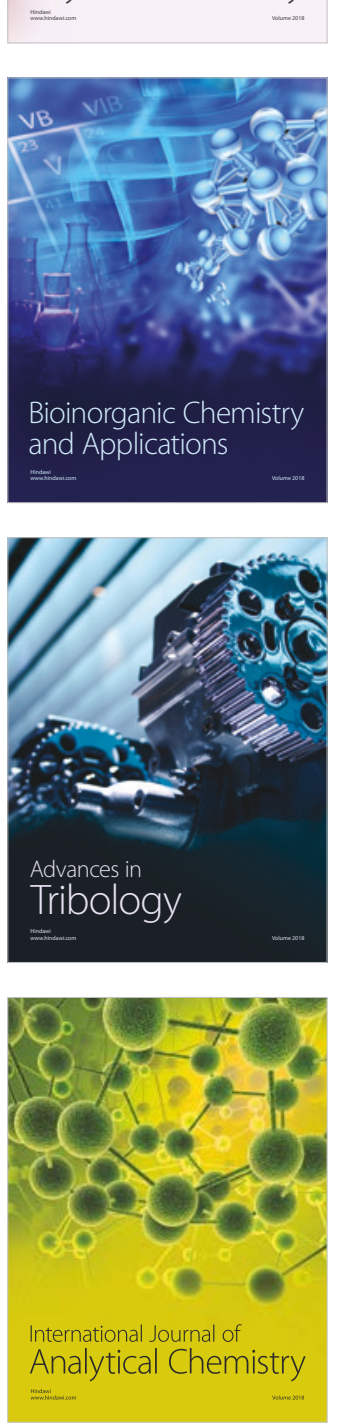

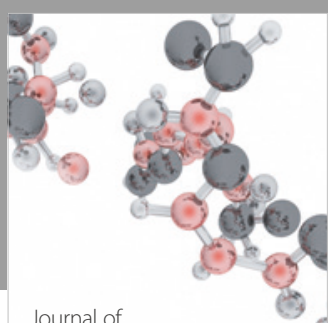

Analytical Methods

in Chemistry

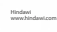

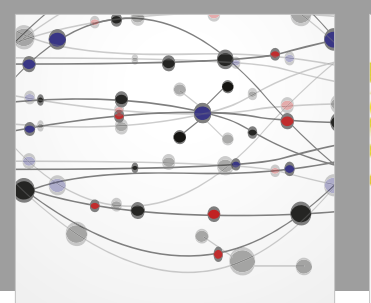

The Scientific World Journal

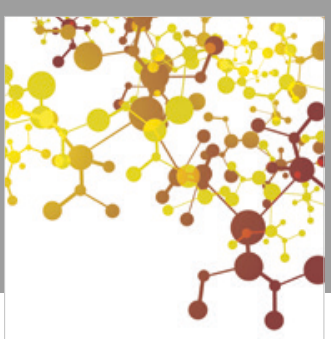

Journal of

Applied Chemistry
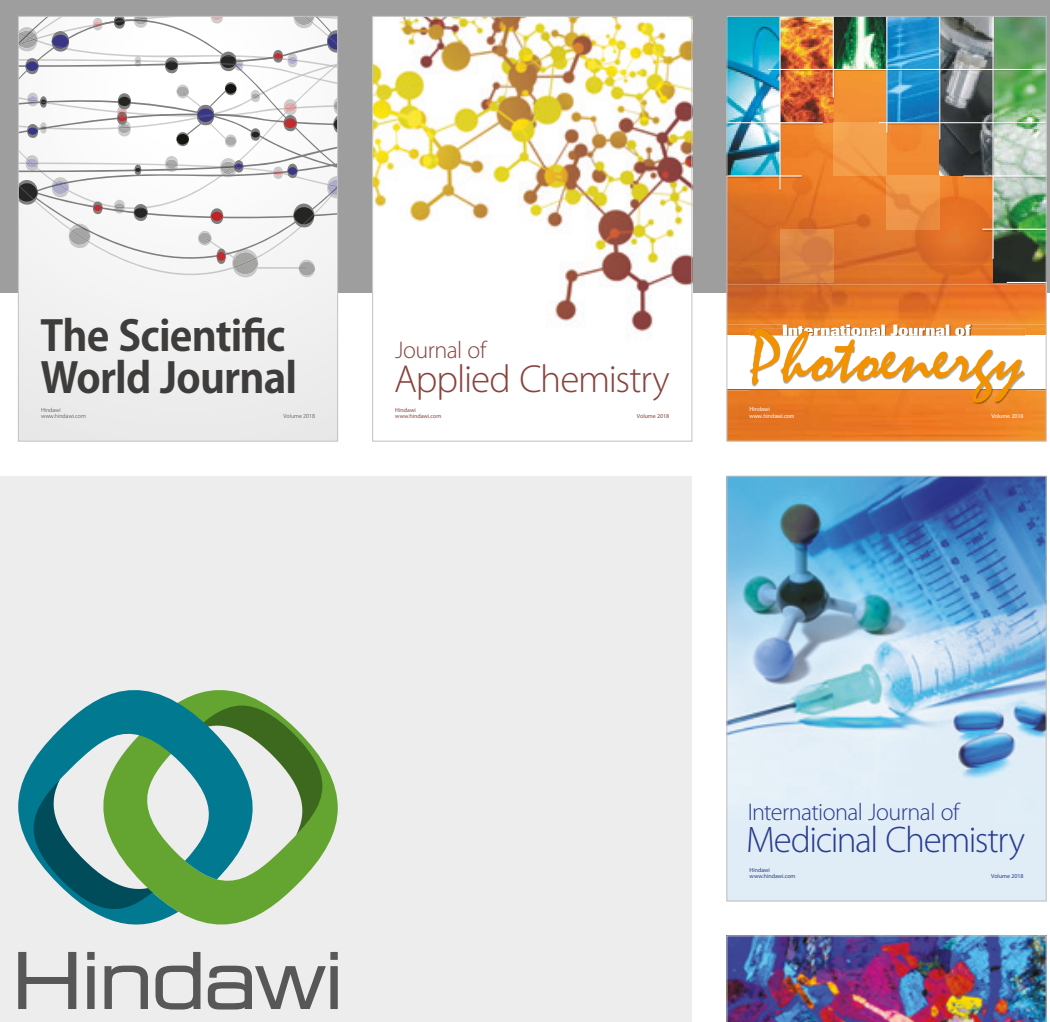

Submit your manuscripts at

www.hindawi.com
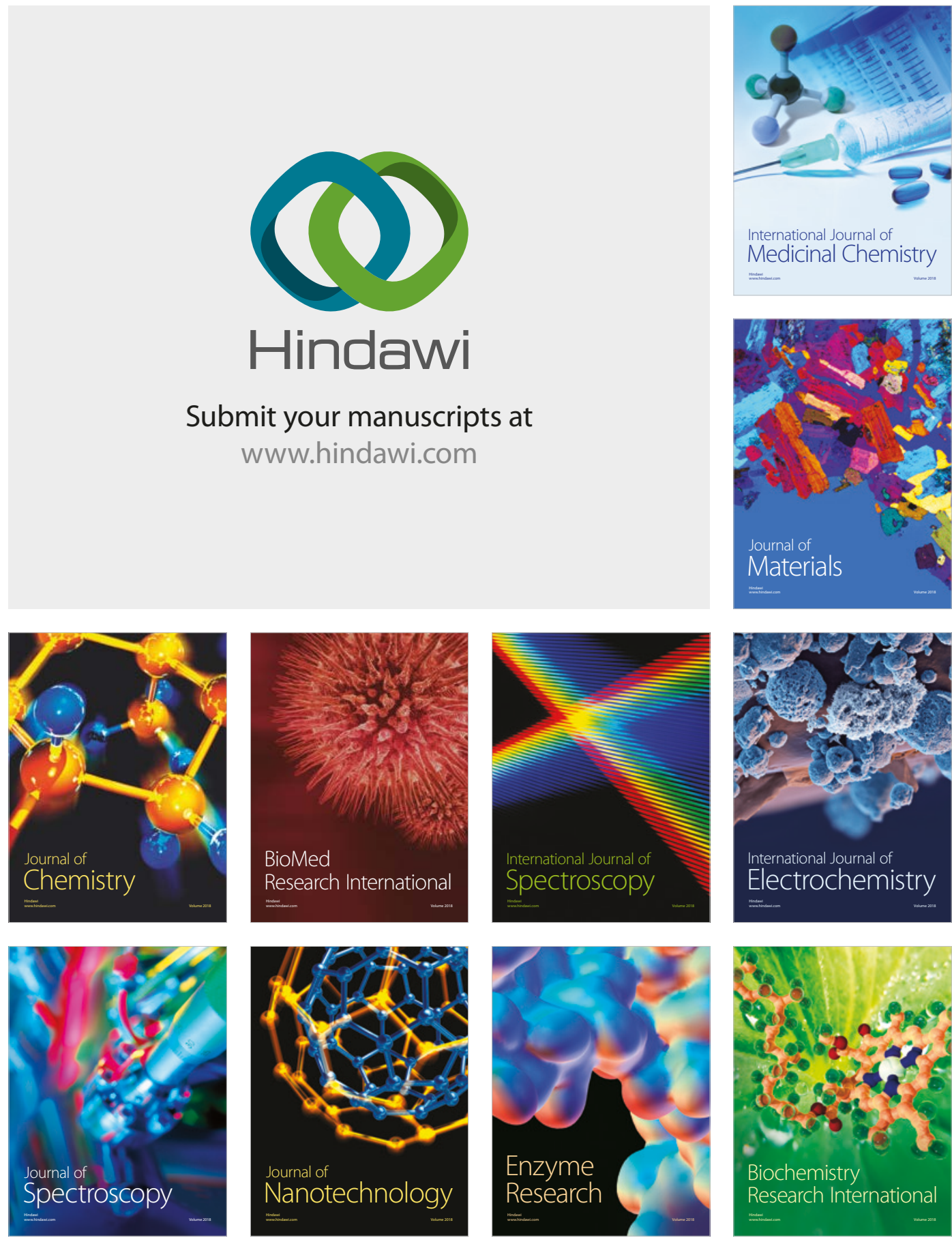
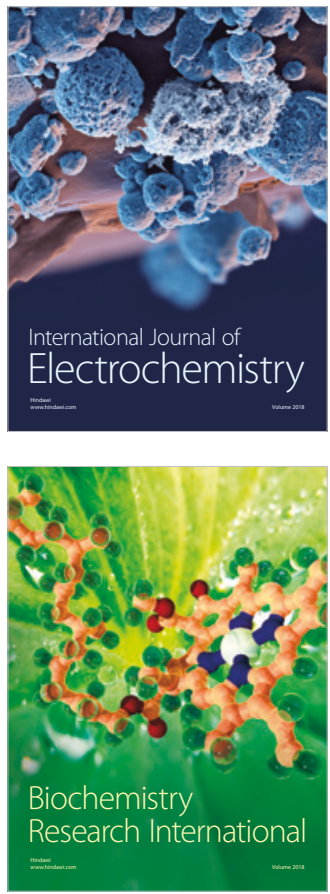